PENDIDIKAN

Publish by: Library of STKIP PGRI Sumatera Barat

E-ISSN : 2775-5770

Vol. 1 No. 4 (November 2021) (622-634)

http://ejournal.stkip-pgri-sumbar.ac.id/index.php/horizon

\title{
PENGARUH PENERAPAN PEMBELAJARAN BLENDED LEARNING TERHADAP HASIL BELAJAR SISWA
}

Zulma Hendra, Alfi Yunita, Ainil Mardiyah

Program Studi Pendidikan Matematika STKIP PGRI Sumatera Barat zulmahendra100@gmail.com

Submitted: 02-09-2021, Reviewed: 17-09-202, Accepted: 21-09-2021

\begin{abstract}
This study aims to determine the effect of the application of blended learning on the learning outcomes of class X MIA students at SMA PGRI 2 Padang. This study used a pre-experimental design in the form of a One-Shot Case Study by taking research subjects by Purposive Sampling. The sample of this research was the students of class X MIA. This study used descriptive questions as a final test instrument. The data analysis technique used in this research was a t-test. Based on the data collection techniques and data analysis carried out, it was obtained that $\mathrm{t}_{\text {count }}=1.81$ and $\mathrm{t}_{\text {table }}=1.68$, because $\mathrm{t}_{\text {count }}>\mathrm{t}_{\text {table }}$, then reject $\mathrm{H}_{0}$ at a significant level of 0.05 so it can be concluded that there is an effect of applying blended learning on studensts' learning outcomes of class X MIA at SMA PGRI 2 Padang.
\end{abstract}

Keywords: Blended Learning, Learning Outcomes.

\section{PENDAHULUAN}

Matematika adalah ilmu umum yang mendasari perkembangan teknologi modern, memiliki fungsi penting dalam berbagai disiplin dan memajukan pola pikir manusia Depdiknas (2016). Matematika lebih memberikan kegiatan penalaran, bukan memberikan hasil eksperimen atau hasil observasi, karena matematika terbentuk karena pikiran manusia yang berhubungan dengan ide, proses serta penalaran. Selaras dengan yang disampaikan oleh Darma (2020: 531), Matematika bukanlah ilmu yang hanya untuk keperluan dirinya sendiri, tetapi ilmu yang bermanfaat untuk sebagian amat besar untuk ilmu-ilmu lain. Dengan makna lain bahwa matematika mempunyai peranan yang sangat penting untuk ilmu lain, seperti sains, teknologi serta pendidikan.

Dalam dunia pendidikan, Pembelajaran matematika merupakan usaha sadar yang dilakukan guru dalam membentuk watak, peradaban, dan meningkatkan mutu kehidupan peserta didik serta membantu siswa 
HORIZON

PENDIDIKAN

Publish by: Library of STKIP PGRI Sumatera Barat

E-ISSN : 2775-5770

Vol. 1 No. 4 (November 2021) (622-634)

http://ejournal.stkip-pgri-sumbar.ac.id/index.php/horizon

dalam belajar matematika yang baik sehingga matematika itu lebih muda dipelajari dan lebih menarik. Pembelajaran matematika lebih menekankan menggunakan konsep, strategi yang matang untuk dapat sampai ke siswa. Menurut Prayitno (2015: 6), kebermaknaan dalam belajar matematika akan muncul manakala aktivitas yang dikembangkan dalam belajar matematika memuat standar proses pembelajaran matematika, yakni pemahaman, penalaran, komunikasi, koneksi, pemecahan masalah, dan representasi.

Pembelaran matematika harus memiliki persiapan dari guru dalam membuat RPP, strategi ataupun metode yang diambil harus tersingkron menjadi satu agar mencapai hasil belajar yang baik. Hasil belajar mempunyai peranan penting dalam proses pembelajaran. Menurut Kayatun (2013) "hasil belajar adalah hasil yang diperoleh oleh siswa setelah melaksanakan proses pembelajaran yang ditunjukkan dengan nilai tes yang diberikan oleh guru setelah selesai memberikan materi pembelajaran pada satu pokok bahasan". Menurut Sembiring (2013: 228) menyatakan bahwa untuk meningkatkan hasil belajar matematika, guru disarankan agar menggunakan strategi pembelajaran yang tepat dan variatif dalam menyajikan materi dan aplikasi matematika dalam kegiatan pembelajaran.

Dewasa ini, guru telah banyak memberikan berbagai metode mengajar dalam proses pembelajaran matematika kepada siswa, namun tidak semua metode mengajar sesuai dengan materi pokok bahasan yang diajarkan. Perkembangan teknologi informasi dan komunikasi di era industri 4.0 telah memiliki dampak besar terhadap proses pembelajaran. Menurut Keengwe and Georgina (2012) dalam penelitiannya menyatakan bahwa perkembangan teknologi memberikan perubahan terhadap proses pengajaran dan pembelajaran. Pembelajaran tersebut dibutuhkan sebagai sarana atau alat untuk mendukung proses pembelajaran yang terjadi saat ini. Salah satu media teknologi yang sering digunakan saat ini adalah aplikasi pada telepon 


\section{Jopana HORIZON} PENDIDIKAN

JURNAL HORIZON PENDIDIKAN

Publish by: Library of STKIP PGRI Sumatera Barat

E-ISSN : 2775-5770

Vol. 1 No. 4 (November 2021) (622-634)

http://ejournal.stkip-pgri-sumbar.ac.id/index.php/horizon

genggam/ponsel. Hasil penelitian Gheytasi, M., Azizifar, A., \& Gowhary (2015) menunjukan bahwa siswa yang banyak berinteraksi dengan aplikasi di telepon genggam lebih mudah memahami isi teks bacaan. Berbagai macam media pembelajaran yang ada namun belum digunakan guru secara maksimal.

Berdasarkan hasil observasi dan wawancara yang dilakukan oleh peniliti diperoleh bahwa siswa telah menggunakan pembelajaran secara normal dimana siswa sudah belajar secara tatap muka dengan waktu belajar didalam proses belajar mengajar itu tidak seperti sebelumnya dimana waktu pembelajaran sebelumnya 90 menit berganti menjadi 60 menit, sehingga pelaksanaanya belum optimal. Oleh karena itu, perlunya inovasi dan perubahan dalam proses pembelajaran terutama media pembelajaran online untuk meningkatkan hasil pembelajaran siswa kombinasi model pembelajaran yang menggabungkan pertemuan tatap muka (offline) dan daring (online)
Model pembelajaran Blended (Blended Learning) menjadi salah satu solusi yang dianggap mampu mengaktifkan atau memancing siswa sesuai dengan kompetensi yang dicapai, karakteristik mata pelajaran, karakteristik siswa, serta sarana dan prasarana baik online maupun tatap muka agar dapat berinteraksi secara maksimal dan dapat mengoptimalkan pemanfaatan penggunaan teknologi dalam dunia pendidikan. Model ini merupakan kombinasi model pembelajaran yang menggabungkan pertemuan tatap muka (offline) dan online system yang dianggap mampu mengaktifkan atau memancing siswa sesuai dengan kompetensi yang dicapai, karakteristik mata pelajaran, karakteristik siswa, serta sarana dan prasarana baik online maupun tatap muka agar dapat berinteraksi secara maksimal (Dewi Permata Sari , Aty Nurdiana, 2019: 2).

\section{METODE PENELITIAN}

Penelitian ini menggunakan pendekatan kuantitatif. Metodenya adalah Pre-Experimental Designs dengan jenis One-Shot Case Study. Menurut Sugiyono (2018: 74) One- 


\section{Jupana \\ HORIZON}

PENDIDIKAN
JURNAL HORIZON PENDIDIKAN

Publish by: Library of STKIP PGRI Sumatera Barat

E-ISSN : 2775-5770

Vol. 1 No. 4 (November 2021) (622-634)

http://ejournal.stkip-pgri-sumbar.ac.id/index.php/horizon

Shot Case Study adalah suatu diberikan

kelompok

Dalam proses penelitian ada

treatment/perlakuan, dan selanjutnya

diobservasi hasilnya (treatment adalah sebagai variabel bebas, dan hasil adalah sebagai variabel terikat). Pada kelompok eksperimen akan menggunakan pembelajaran kurikulum 2013 dengan penerapan pembelajaran Blended Learning .

Penelitian ini dilaksanakan pada semester Genap pada tanggal 1 Maret 2021 sampai 29 Maret 2021 di kelas X MIA SMA PGRI 2 Padang Tahun Pelajaran 2020/2021.

Populasi dalam penelitian ini adalah siswa SMA PGRI 2 Padang Kelas X Tahun Ajaran 2020/2021 yang berjumlah 54 siswa. Sedangkan sampel penelitian dipilih secara Purposive Sampling dan hasil diskusi bersama guru mata pelajaran matematika serta direkomendasikan oleh kepala sekolah SMA PGRI 2 Padang yaitu kelas X MIA SMA PGRI 2 Padang yang berjumlah 27 siswa karena diketahui bahwa kemampuan siswa lebih baik dari pada kelas lainnya.

1. Prosedur beberapa tahapan dan juga ikhtiar usaha yang penulis tempuh agar memperoleh hasil yang optimal. Adapun tahapan-tahapan dalam prosedur penelitian ini adalah sebagai berikut :

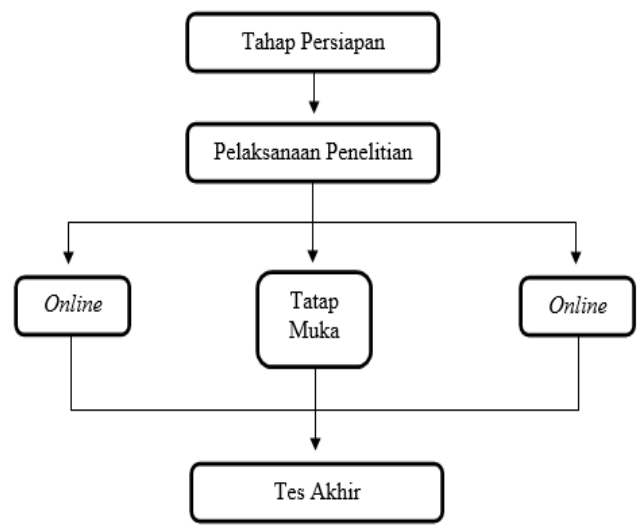

Gambar 1. Prosedur Penelitian

2. Instrumen Penelitian

Instrumen adalah alat atau fasilitas yang digunakan penelitian dalam mengumpulkan data agar pekerjaannya lebih mudah dan hasilnya lebih baik, sehingga mudah diolah (Arikunto, 2010). Untuk memperoleh data yang akan diolah maka penulis menggunakan instrumen penelitian sebagai berikut:

a. Tes Hasil Belajar Siswa

1) Menyusun Tes

Tes yang diberikan tes tertulis berupa soal-soal dalam bentuk uraian berdasarkan pokok 
PENDIDIKAN

Publish by: Library of STKIP PGRI Sumatera Barat

E-ISSN : 2775-5770

Vol. 1 No. 4 (November 2021) (622-634)

http://ejournal.stkip-pgri-sumbar.ac.id/index.php/horizon

bahasan yang telah dipelajari.

Tes tersebut berfungsi untuk

mengukur

kemampuan

pemahaman konsep siswa

terhadap materi yang telah

dipelajari. Dalam tes tersebut

dilakukan langkah-langkah

sebagai berikut: (a) Menentukan

tujuan melakukan tes yaitu untuk

mengetahui tingkat kemapuan

pemahaman konsep matematika

siswa, (b) Membuat batasan dari materi pelajaran yang akan diuji,

(c) Membuat kisi-kisi soal tes akhir sesuai dengan indikator kemampuan pemahaman konsep.

2) Validitas Tes

Validitas tes dalam penelitian ini menggunakan validitas isi atau validitas kurikulum. Tes yang disusun dalam penelitian ini berdasarkan kurikulum dan materi yang telah diajarkan oleh guru serta didahului dengan pembuatan kisi-kisi soal. Soal divalidasi oleh dosen pembimbing dan guru yang mengajar disekolah penelitian.

3) Melakukan Uji Coba Tes.

Hasil dari sebuah penelitian dapat dipercaya apabila alat pengumpul data yang digunakan betul-betul akurat dan sudah memiliki validitas, indeks kesukaran soal dan daya pembeda soal yang baik, maka soal itu perlu dilakukan uji coba terlebih dahulu di sekolah yang memiliki kualifikasi dan kemampuan akademik yang sama dengan sekolah yang akan diadakan penelitian. Uji coba tes dilakukan di SMA PGRI 4 Padang, karena berdasarkan informasi yang diiperoleh dari wakil kepala sekolah dibidang kurikulum dan guru matematika SMA PGRI 2 Padang dan SMA PGRI 4 Padang, bahwa kedua sekolah tersebut memiliki kemampuan yang tidak jauh berbeda dan memiliki KKM yang sama yaitu 76. Tujuan dari uji coba soal tes dilakukan adalah supaya tes yang diberikan mempunyai kualitas yang baik bagi kelas penelitian. Uji coba tes dilakukan di SMA PGRI 4 Padang pada tanggal 23 Maret 2021 di kelas X IPA dengan jumlah siswa sebanyak 10 orang. 
Publish by: Library of STKIP PGRI Sumatera Barat

E-ISSN : 2775-5770

Vol. 1 No. 4 (November 2021) (622-634)

http://ejournal.stkip-pgri-sumbar.ac.id/index.php/horizon

4) Melakukan Analisis Item

Setelah uji coba dilakukan kegiatan selanjutnya adalah melakukan analisis butir soal, untuk melihat keberadaan soalsoal yang disusun baik atau tidak.

Dengan analisa soal dapat diperoleh informasi tentang kejelekan sebuah soal dan petunjuk untuk mengadakan perbaikan”. Komponen yang perlu diperhatikan dalam melakukan analisis butir item adalah tingkat kesukaran, daya pembeda, serta reliabilitas tes.

a) Tingkat Kesukaran Butir Soal

Agar tes dapat digunakan secara luas, setiap soal harus diselidiki tingkat kesukarannya.

Hasil perhitungan soal uji coba dapat dilihat pada Tabel 1:

Tabel 1. Kriteria Tingkat Kesukaran Soal

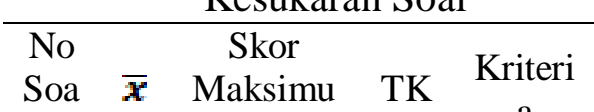

\begin{tabular}{ccccc}
1 & & $\mathrm{~m}$ & & $\mathrm{a}$ \\
\hline 1 & 1 & 20 & 0,8 & Muda
\end{tabular}

$\begin{array}{llll}7 & 5 & \mathrm{~h}\end{array}$

$\begin{array}{lllll}2 & 3 & 20 & 0,1 & \text { Sukar }\end{array}$

$\begin{array}{lllcl} & 2 & & 5 & \\ & 2 & 30 & 0,7 & \text { Muda }\end{array}$

$\begin{array}{lll}2 & 3 & h\end{array}$

$\begin{array}{lllll}4 & 2 & 30 & 0,8 & \text { Muda }\end{array}$

$4 \quad \mathrm{~h}$

Berdasarkan Tabel 1 di atas diperoleh tingkat kesukaran soal pada soal nomor 1 adalah 0,85 dengan kriteria tergolong soal mudah, soal nomor 2 adalah 0,15 dengan kriteria tergolong soal sukar, soal nomor 3 adalah 0,73 dengan kriteria tergolong soal mudah dan soal nomor 4 adalah 0,8 dengan kriteria tergolong soal mudah, dan pada nomor 2 tergolong sukar.

a) Daya Pembeda Soal (DP)

Untuk perhitungan pengolahan soal uji coba tes didapatkan daya beda soal tersebut dapat dilihat pada Tabel 2:

Tabel 2. Kriteria Daya Pembeda Soal

\begin{tabular}{|c|c|c|c|c|c|}
\hline $\begin{array}{c}\mathrm{N} \\
\mathrm{o} \\
\text { So } \\
\text { al }\end{array}$ & $\begin{array}{c}\overline{\boldsymbol{x}} \\
\text { Kelo } \\
\text { mpok } \\
\text { Atas }\end{array}$ & $\begin{array}{c}\overline{\boldsymbol{x}} \\
\text { Kelo } \\
\text { mpok } \\
\text { Bawa } \\
\mathrm{h} \\
\end{array}$ & $\begin{array}{l}\text { Sk } \\
\text { or } \\
\text { To } \\
\text { tal }\end{array}$ & $\begin{array}{l}\mathrm{D} \\
\mathrm{P}\end{array}$ & Kriteria \\
\hline 1 & 20 & 14 & 20 & $\begin{array}{l}0, \\
3\end{array}$ & $\begin{array}{c}\text { Soal } \\
\text { diterim } \\
\text { a tetapi } \\
\text { perlu } \\
\text { diperba } \\
\text { iki }\end{array}$ \\
\hline 2 & 6 & 0 & 20 & $\begin{array}{l}0, \\
3\end{array}$ & $\begin{array}{c}\text { Soal } \\
\text { diterim } \\
\text { a tetapi } \\
\text { perlu } \\
\text { diperba } \\
\text { iki }\end{array}$ \\
\hline 3 & 30 & 14 & 30 & $\begin{array}{l}0, \\
5\end{array}$ & $\begin{array}{c}\text { Soal } \\
\text { diterim } \\
\text { a/baik }\end{array}$ \\
\hline 4 & 30 & 18 & 30 & $\begin{array}{c}0 \\
4\end{array}$ & $\begin{array}{c}\text { Soal } \\
\text { diterim } \\
\text { a/baik }\end{array}$ \\
\hline
\end{tabular}


HORIZON

PENDIDIKAN

Publish by: Library of STKIP PGRI Sumatera Barat

E-ISSN : 2775-5770

Vol. 1 No. 4 (November 2021) (622-634)

http://ejournal.stkip-pgri-sumbar.ac.id/index.php/horizon

Berdasarkan Tabel 2 di atas terlihat soal nomor 1 dan 2 dengan daya pembeda nya adalah 0,3 dengan kriteria diterima tetapi perlu diperbaiki, soal nomor 3 dan 4 daya pembedanya adalah 0,5 dan 0,4 dengan kriteria soal diterima/baik. Semua daya pembeda soal besar besar dari 0,3, maka diperoleh semua soal diterima dengan baik.

b) Reliabilitas Tes

Reliabilitas tes adalah suatu ukuran apakah tes tersebut dapat dipercaya. Sudjana (2010: 120) mengatakan bahwa "Reliabilitas alat ukur adalah ketepatan alat tersebut dalam mengukur apa yang diukurnya. Artinya, kapan pun alat ukur tersebut digunakan akan memberikan hasil ukur yang sama". Untuk melihat reliabelitas dari soal tersebut dapat dilihat pada Tabel 3:

Tabel 3. Reliabilitas Soal Uji Coba

\begin{tabular}{cccc}
\hline No Soal & $\boldsymbol{\Sigma} \boldsymbol{x}$ & $\boldsymbol{\Sigma} \boldsymbol{x}^{2}$ & $\begin{array}{c}\text { Variansi } \\
\text { Setiap } \\
\text { Item } \\
\left(\boldsymbol{\sigma}_{i}^{\mathbf{2}}\right)\end{array}$ \\
\hline 1 & 170 & 3100 & 21 \\
2 & 30 & 500 & 41 \\
3 & 220 & 6400 & 156 \\
4 & 240 & 6800 & 104 \\
\hline Jumlah & & & 322 \\
\hline
\end{tabular}

Berdasarkan Tabel 3 di atas disimpulkan bahwa soal tes uji coba diperoleh $\quad r_{11}=0,70 \quad$ sedangkan $r_{\text {tabel }}=0,632, \quad r_{11}>r_{\text {tabel }}$. $(0,70>0,632)$ maka instrumen tersebut dikatakan reliabel atau instrument dapat dipercaya.

3. Teknik Analisis Data

Analisis data bertujuan untuk menguji hipotesis yang diajukan, apakah diterima atau ditolak. Disamping itu analisis ini digunakan untuk mendapatkan informasi tentang hasil belajar siswa. Pada penelitian ini diperoleh data yang berasal dari instrumen penelitian yaitu tes akhir. Hasil belajar siswa diperoleh dari hasil tes akhir. Adapun langkah-langkah yang digunakan dalam analisis data adalah sebagai berikut.

1. Menghitung Skor Hasil Belajar Siswa

Perhitungan dilakukan untuk memperoleh informasi tentang hasil belajar siswa yang dinilai dari tes akhir yang diberikan pada kelas eksperimen. Perhitungan penilaian pada tes akhir menggunakan Rubrik Holistik dengan skala 4. Iryanti (2004: 13) mengungkapkan bahwa "Rubrik Holistik adalah pedoman untuk menilai berdasarkan kesan 


\section{Jubana HORIZON}

PENDIDIKAN

JURNAL HORIZON PENDIDIKAN

Publish by: Library of STKIP PGRI Sumatera Barat

E-ISSN : 2775-5770

Vol. 1 No. 4 (November 2021) (622-634)

http://ejournal.stkip-pgri-sumbar.ac.id/index.php/horizon

keseluruhan atau kombinasi semua kriteria".

Tabel 4. Rubrik Holistik

\begin{tabular}{cccc}
\hline 0 & 1 & 2 & 3 \\
\hline Tidak & Banyak & Sedikit & Betul \\
menjaw & kesalah & kesalah & semua \\
ab & an & an & dalam \\
sama & dalam & dalam & menjaw \\
sekali & menjaw & menjaw & ab \\
& ab & ab & pertany \\
& pertany & pertany & aan \\
& aan & aan & \\
\hline Sumber : & Dimodifikasi dari & Iryanti \\
& \multicolumn{4}{c}{ (2004: 13) }
\end{tabular}

Berdasarkan skala yang sudah dibuat dapat dinilai tes akhir yang dilakukan siswa. Skor yang diperoleh siswa dirubah ke dalam skala angka yang ditetapkan (dalam 0-100). Skor yang diperoleh siswa dikonversikan ke skala 0-100 yaitu :

$$
\text { Nilai Siswa }=\frac{\text { Skor yang Diperoleh Siwa }}{\text { Skor Maksimum }} \times 100
$$

2. Analisis Data Pengaruh Penerapan Blended Learning terhadap Hasil Belajar Siswa

Analisis data bertujuan untuk menguji hipotesis yang diajukan, apakah signifikan atau tidak signifikan. Uji hipotesis bertujuan untuk apakah terdapat pengaruh penerapan Blended Learning terhadap hasil belajar matematika siswa. Berdasarkan hipotesis yang dikemukan, maka dilakukan uji t dengan statistic uji yang diajukan.

Pengujian tersebut digunakan uji statistic seperti yang dikemukan oleh Arikunto (2010:124) yaitu:

$$
\begin{gathered}
t=\frac{x_{1}-x_{2}}{S_{x_{1}}-S_{x_{2}}} \text { dengan } \\
S=\sqrt{\frac{\sum x^{2}-\frac{\left(\sum x\right)^{2}}{n}}{n-1}}
\end{gathered}
$$

\section{HASIL DAN PEMBAHASAN}

1. Hasil Penelitian

Pelaksanaan tes akhir dilakukan pada kelas penelitian yaitu X MIA yang diikuti oleh 19 orang siswa. Setelah dilaksanakan tes akhir diperoleh data tentang hasil belajar matematika siswa. Berdasarkan perhitungan didapat nilai rata-rata $(x)$, skor tertinggi $\left(x_{\max }\right)$, skor terendah $\left(x_{\min }\right)$, tes akhir pada kelas eksperimen sesuai dengan Tabel 5.

Tabel 5. Tes Akhir Kelas Eksperimen

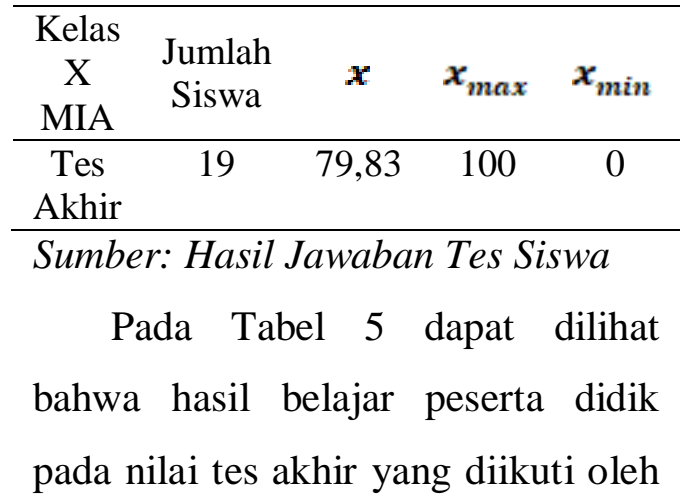


HORIZON

PENDIDIKAN

JURNAL HORIZON PENDIDIKAN

Publish by: Library of STKIP PGRI Sumatera Barat

E-ISSN : 2775-5770

Vol. 1 No. 4 (November 2021) (622-634)

http://ejournal.stkip-pgri-sumbar.ac.id/index.php/horizon

19 siswa diperoleh rata-rata adalah 79,83 dengan nilai tes akhir tertinggi adalah 100 dan nilai nilai terendahnya adalah 0 .

2. Pembahasan

Hipotesis dalam penelitian ini adalah "terdapat pengaruh penerapan pembelajaran Blended Learning terhadap hasil belajar siswa kelas $\mathrm{X}$ MIA di SMA PGRI 2 Padang”. Sebelum menguji hipotesis terlebih dahulu dilakukan pengambilan data pre-test dan pemberian treatment terhadap kelas eksperimen serta diberikan post-test terhadap siswa yang ada dikelas eksperimen setelah diberikan treatment. Berdasarkan hasil perhitungan dan analisis tes akhir terdapat bahwa rata-rata hasil belajar matematika siswa untuk kelas eksperimen 79,83 dan simpangan baku 28,91 dengan skor tertinggi 100 dan skor terendah 0. Maka diperoleh $t_{\text {hitung }}>t_{\text {tabel }}=1,81>1,68$ sehingga tolak $H_{0}$ pada taraf 0,05 . Sehingga hipotesis diterima yang berbunyi terdapat pengaruh penerapan pembelajaran Blended Learning terhadap hasil belajar siswa kelas X MIA di SMA PGRI 2 Padang.
Proses pembelajaran tatap muka dilakukan di sekolah menggunakan pembelajaran Blended Learning dengan sistem pembelajaran langsung dengan metode pendekatan saintifik memiliki tiga tahap utama yaitu: (1) Online, Memberikan LKPD di aplikasi Google Classroom serta menyampaikan tujuan pembelajaran yang akan dicapai. Berikut Gambar 2 pemberian LKPD di aplikasi Google Classroom.

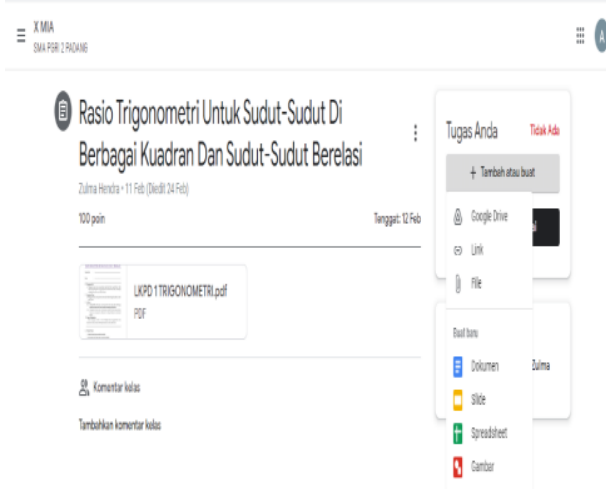

Gambar 2. Pemberian LKPD di aplikasi Google Classroom

Setelah siswa masuk ke kelas online di aplikasi Google Classroom dan guru telah memberikan LKPD di aplikasi Google Classroom tersebut, maka pelaksanaan pembelajaran dilanjutkan ke tahap kedua. (2) Tatap Muka, Proses pembelajaran tatap muka dilakukan di sekolah dengan menggunakan pembelajaran 
HORIZON

PENDIDIKAN

Publish by: Library of STKIP PGRI Sumatera Barat

E-ISSN : 2775-5770

Vol. 1 No. 4 (November 2021) (622-634)

http://ejournal.stkip-pgri-sumbar.ac.id/index.php/horizon

langsung dengan metode pendekatan saintifik tercantum dalam Lembar Kerja Peserta Didik (LKPD). Saintifik dalam pembelajaran meliputi mengamati, menanya, mengumpulkan informasi/mencoba, mengasosiasi, dan mengomunikasikan.

Diawal pembelajaran guru memeriksa kehadiran siswa sebagai sikap disiplin, guru juga meminta siswa untuk mendownload LKPD yang ada di Google Classroom dan membaca sekilas, setelah itu guru memberikan apersepsi dan motivasi terhadap pembelajaran sebagai kegiatan pembuka dalam proses belajar mengajar.

Metode awal dalam kegiatan inti adalah kegiatan mengamati, dimana guru memberikan motivasi atau rangsangan terlebih dahulu untuk memusatkan perhatian pada materi rasio trigonometri pada sudut-sudut berelasi dengan cara mengamati dan membaca LKPD yang telah di download pada aplikasi Google Classroom, guru memberikan kesempatan kepada siswa untuk mengidentifikasi pertanyaan yang muncul dari materi rasio trigonometri pada sudut-sudut berelasi, setelah siswa mengamati dan membaca LKPD yang di download tersebut, setelah siswa menyelesaikan pertanyaan yang ada dan siswa mengumpulkan informasi sesuai langkah-langkah yang ada di LKPD. Setelah itu, siswa yang diminta menyelesaikan permasalahan yang berkaitan dengan kehidupan seharisehari untuk mendapatkan informasi dan mengolah data informasi tersebut kedalam tabel atau kolom yang ada di LKPD yang ada pada materi rasio trigonometri pada sudut-sudut berelasi. Siswa yang telah bisa memahami materi rasio trigonometri pada sudut-sudut berelasi, maka siswa diminta untuk bisa mengkomunikasikan apa yang didapatkan dalam pembelajaran. Kegiatan ini dapat dilakukan dengan menuliskan atau menceritakan apa yang ditemukan dalam kegiatan mencari informasi, mengasosiasi, dan menemukan pola. Hasil tersebut disampaikan di depan kelas dan dinilai oleh guru sebagai hasil belajar siswa.

Kegiatan penutup dalam pembelajaran tersebut dilakukan oleh 
HORIZON

PENDIDIKAN

Publish by: Library of STKIP PGRI Sumatera Barat

E-ISSN : 2775-5770

Vol. 1 No. 4 (November 2021) (622-634)

http://ejournal.stkip-pgri-sumbar.ac.id/index.php/horizon

guru dengan cara guru memberikan refleksi setelah siswa menjawab latihan yang ada di LKPD, guru dan siswa sama-sama menyimpulkan hasil kegiatan pembelajaran mengenai rasio trigonometri pada sudut-sudut berelasi serta guru meminta siswa untuk mendownload LKPD pada aplikasi Google Classroom untuk materi identitas trigonometri sebagai materi selanjutnya dan guru juga meminta siswa untuk mengerjakan tugas rumah yang ada di LKPD dan di upload pada aplikasi Google Classroom. Setelah semua itu selesai, guru menutup kegiatan pembelajaran dengan doa dan salam. Dengan kegiatan penutup pada tahap tatap muka tersebut, maka pembelajaran selanjutnya masuk ke tahap ketiga. (3) Online, Pembelajaran tatap muka dilaksanakan selama 60 menit, sehingga untuk melaksanakan tugas rumah dilakukan di rumah lalu guru meminta siswa untuk mengerjakan tugas (PR) di rumah dan dikumpul dalam bentuk online (pdf/ jpg) dan diupload kembali ke aplikasi Google Classroom. Berikut Gambar 3 tampilan tugas yang diberikan siswa ke dalam aplikasi Google Classroom.

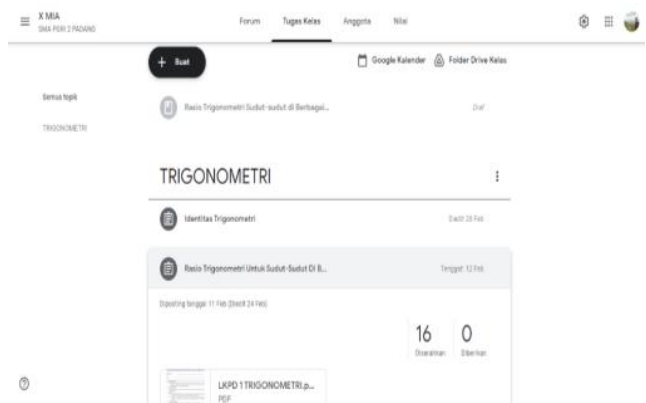

Gambar 3. Tampilan Tugas yang Diberikan Siswa

Gambar 3 menunjukkan adanya aktivitas siswa didalam aplikasi Google Classroom yaitu pemberian tugas. Ada 16 siswa yang telah memberikan tugas kepada guru melalui aplikasi Google Classroom.

Proses penelitian dilaksanakan dengan menerapkan pembelajaran Blended Learning dengan menggunakan pembelajaran langsung, sehingga bisa memberikan pembelajaran yang cukup efektif ditengah waktu proses pembelajaran di sekolah yang telah menjadi 60 menit. Dengan dibaginya menjadi tiga bagian, online, tatap muka, online, namun proses tersebut masih ada kendala seperti kesiapan siswa yang belum maksimal untuk menggabungkan pembelajaran online dengan tatap muka dan masih adanya 
HORIZON

PENDIDIKAN
JURNAL HORIZON PENDIDIKAN

Publish by: Library of STKIP PGRI Sumatera Barat

E-ISSN : 2775-5770

Vol. 1 No. 4 (November 2021) (622-634)

http://ejournal.stkip-pgri-sumbar.ac.id/index.php/horizon siswa yang tidak meng-upload tugas

yang telah diberikan.

\section{KESIMPULAN}

Berdasarkan hasil penelitian, pembahasan dan analisis data yang dikemukakan dapat disimpulkan bahwa terdapat pengaruh penerapan pembelajaran Blended Learning terhadap hasil belajar matematika siswa kelas X MIA SMA PGRI 2 Padang.

\section{DAFTAR PUSTAKA}

Arikunto, S. (2010). Prosedur Penelitian. Rineka Cipta.

Darma, I. K., Karma, I. G. M., \& Santiana, I. M. A. (2020). Blended Learning, Inovasi Strategi Pembelajaran Matematika di Era Revolusi Industri 4. O Bagi Pendidikan Tinggi. 3, 527-539.

Depdiknas. (2006). Permendiknas no 22 tahun 2006 Tentang Standar Isi. Depdiknas.

Dimyati dan Mudjiono. (2006). Belajar dan Pembelajaran. Rineka Cipta, 2006.

Dwiyogo, D. W. (2018). Pembelajaran Berbasis Blended Learning. Rajawali Pers.

Gheytasi, M., Azizifar, A., \& Gowhary, H. (2015). The Effect of Smartphone on the Reading
Comprehension Proficiency of Iranian EFL Learners. Procedia - Social and Behavioral Sciences, 199(1), 225-230.

Iryanti, P. (2004). Penilaian Unjuk Kerja. 41.

Jowita, V. N. (2017). Pengembangan Lembar Kerja Peserta Didik ( LKPD ) Menggunakan Model Problem Based Learning Pada Tema 4 Sehat Itu Penting Subtema 3 Lingkungan Sehat di Kelas V. Artikel Ilmiah Pendidikanm PGSD, 1-10.

Kayatun, S. (2013a). Penggunaan Metode Kerja Kelompok untuk Meningkatkan Hasil Belajar Matematika Sekolah Dasar. Jurnal Pendidikan Dan Pembelajaran.

Keengwe, J., \& Georgina, D. (2012). The digital course training workshop for online learning and teaching. 365-379. https://doi.org/10.1007/s10639011-9164-x

Muliyardi. (2002). Strategi Pembelajaran Matematika. FMIPA UNP.

Prayitno, W. (2015). Implementasi Blended Learning dalam Pembelajaran pada Pendidikan Dasar dan Menengah. Artikel LPMP D.I. Yogyakarta, 1-14.

Sudjana. (2010). Metoda Statistika. Tasito.

Sugiyono. (2018). Metode Penelitian Kuantitatif. Kualitatif, dan $R \& D$. ALFABETA CV. 
Publish by: Library of STKIP PGRI Sumatera Barat

E-ISSN : 2775-5770

Vol. 1 No. 4 (November 2021) (622-634)

http://ejournal.stkip-pgri-sumbar.ac.id/index.php/horizon

Trianto. (2012). Mendesain Model

Pembelajaran Inovatif-

Progresif. Kencana Prenada Media Grup.
Zainun, Y. (2020). Pengembangan Lembar Kerja Peserta Didik (LKPD) Pembelajaran Matematika Dengan Metode Guided Note Taking di SMP. Universitas Muhammdiyah Sumatera Utara. 